\title{
Desempenho agronômico de alface orgânica influenciado pelo sombreamento, época de plantio e preparo do solo no Acre
}

\author{
Eliana Mara Napoli Correia de Paula da Silva(1), Regina Lúcia Félix Ferreira(2), \\ Ana Maria Alves de Souza Ribeiro(2), Sebastião Elviro de Araújo Neto( ${ }^{(2)}$ e Jorge Ferreira Kusdra(2)
}

(1)Secretaria de Estado de Extensão Agroflorestal e Produção Familiar, Avenida Nações Unidas, no 1.140, Estação Experimental, CEP 69915-630
Rio Branco, AC, Brasil. E-mail: eliananapoli@hotmail.com (2)Universidade Federal do Acre, BR 364, Km 04, CEP 69915-900 Rio Branco, AC, Brasil.
E-mail: reginalff@yahoo.com.br, anamaria-ac@bol.com.br, selviro2000@yahoo.com.br, j.f.k@terra.com.br

Resumo - O objetivo deste trabalho foi avaliar o desempenho agronômico do cultivo de alface orgânica sob diferentes níveis de sombreamento, épocas de plantio e preparo do solo, no Acre. Para cada cultivar de alface avaliada, lisa (Baba de Verão) e crespa (Vera), foram instalados quatro experimentos em ambientes com níveis distintos de sombreamento (casa de vegetação, 35\%; tela, 50\%; latada de maracujazeiro, $52 \%$; e a pleno sol), em duas épocas de plantio (estiagem e chuvosa). Utilizou-se o delineamento de blocos ao acaso, com três métodos de preparo do solo (plantio direto, cultivo mínimo e preparo convencional) e quatro repetições. O cultivo em casa de vegetação proporciona maior massa de matéria fresca e produtividade de alface 'Vera', e desempenho similar ao observado sob tela de sombreamento, com preparo mínimo do solo, para as duas épocas de plantio avaliadas. O cultivo a pleno sol, em plantio direto, proporciona maior massa de matéria fresca e produtividade de alface 'Vera', para o período de estiagem. A massa de matéria seca da parte aérea das cultivares Baba de Verão e Vera é maior em cultivo em casa de vegetação, seguida do cultivo sob tela de sombreamento.

Termos para indexação: Lactuca sativa, agricultura orgânica, luminosidade, plantio direto.

\section{Agronomic performance of organic lettuce crop influenced by shading, planting times, and tillage, in the state of Acre, Brazil}

\begin{abstract}
The objective of this work was to evaluate the agronomic performance of organic lettuce crop, under different levels of shading, planting times, and tillage, in the state of Acre, Brazil. For each lettuce cultivar evaluated, smooth (Baba de Verão) and curly (Vera), four experiments were established in environments with different levels of shading (greenhouse, 35\%; screen, 50\%; passion fruit trellis, 52\%; and in full sun), in two growing seasons (dry and rainy). A randomized complete block design was used, with three tillage methods (no-tillage, minimum tillage, and conventional tillage) and four replicates. Cultivation in greenhouse provides higher fresh matter mass and yield of 'Vera' lettuce, and similar performance to that observed under screen shade with minimum soil tillage, for both planting dates evaluated. Cultivation in full sun, under no-tillage, provides higher fresh matter mass and yield of 'Vera' lettuce during the dry season. Shoot dry matter mass of the Baba de Verão and Vera cultivars is higher in cultivation in greenhouse, followed by cultivation under screen shade.
\end{abstract}

Index terms: Lactuca sativa, organic agriculture, luminosity, no-tillage.

\section{Introdução}

A produção e o consumo de hortaliças orgânicas têm aumentado no Brasil, principalmente em razão do seu maior teor de vitamina $\mathrm{C}$ e menor teor de nitrato, quando produzidas sem agroquímicos (Silva et al., 2011). Segundo Barbosa et al. (2011), em Goiânia, 69\% das pessoas entrevistadas consomem produtos orgânicos e $92,6 \%$ tem conhecimento desses alimentos. Contudo, 93\% dos consumidores reclamam da pequena oferta e, consequentemente, dos preços mais elevados, apesar de o custo de produção de hortaliças orgânicas ser $25 \%$ inferior ao da horticultura convencional (Souza, 2005).
Para minimizar esse problema de baixa oferta de hortaliças orgânicas, em determinadas regiões e épocas do ano, faz-se necessário aprimorar tecnologias como o condicionamento climático para plantas, sobretudo para espécies como a alface (Lactuca sativa L.), que apresentam baixa produtividade e qualidade quando cultivadas no verão. Por ser proveniente de clima temperado, a espécie, sob altas temperaturas e luminosidade, desenvolve pendoamento precoce e folhas amargas, fibrosas e pequenas (Bezerra Neto et al., 2005).

O clima no Acre, equatorial quente, úmido e chuvoso, compromete a produtividade dessa hortaliça, 
que é muito sensível às adversidades meteorológicas da região. Nas condições do Estado, a produtividade de alface em cultivo convencional varia de 110 a $198 \mathrm{~g}$ por planta, em período chuvoso, e de 192 a 373 g por planta, em período de estiagem (Lédo et al., 2000); em sistema orgânico, a produtividade varia de 171,7 a 272,1 g por planta (Ferreira et al., 2014).

Além de ser afetada pelos danos causados pela precipitação, a produtividade da alface também é reduzida por fotoinibição, causada por luminosidade elevada (Fu et al., 2012). A espécie requer sombreamento para produção de maior quantidade de massa fresca por planta (Radin et al., 2004), decorrente da diminuição do tecido paliçádico e do aumento do lacunoso, o que aumenta a área foliar específica (Puiatti \& Finger, 2005).

O controle das variáveis meteorológicas, como precipitação (Lédo et al., 2000) e luminosidade (Bezerra Neto et al., 2005), bem como a seleção de cultivares de alface adaptadas a determinadas condições ambientais (Lédo et al., 2000), é fundamental para garantir melhor qualidade e maior produção dessa hortaliça.

Além disso, o manejo adequado do solo, associado à data de plantio e ao acondicionamento climático com sombreamento (Bezerra Neto et al., 2005), também é essencial para aumentar a produtividade e melhorar a qualidade da alface cultivada em condições tropicais, como no Acre (Ferreira et al., 2009).

O objetivo deste trabalho foi avaliar o desempenho agronômico de duas cultivares de alface, lisa (Baba de Verão) e crespa (Vera), no Acre, sob diferentes níveis de sombreamento, épocas de plantio e preparo do solo em sistema orgânico.

\section{Material e Métodos}

Os experimentos foram conduzidos na área experimental do Setor de Agricultura Ecológica da Universidade Federal do Acre, no Município de Rio Branco, AC (9 $57^{\prime} 35^{\prime \prime S}, 67^{\circ} 52^{\prime} 08^{\prime \prime} \mathrm{W}$, a $150 \mathrm{~m}$ de altitude). O clima, conforme a classificação de Köppen, é do tipo Am, quente e úmido, com temperatura média anual em torno de $24,5^{\circ} \mathrm{C}$, umidade relativa do ar de $84 \%$ e precipitação de 1.700 a $2.400 \mathrm{~mm}$.

Para as duas cultivares de alface avaliadas, foram instalados quatro experimentos em ambientes com níveis distintos de sombreamento (casa de vegetação, $35 \%$; tela, $50 \%$; latada de maracujazeiro, $52 \%$; e a pleno sol), em duas épocas de plantio (estiagem e chuvosa) (Tabela 1). Utilizou-se o delineamento de blocos ao acaso, com três métodos de preparo do solo (plantio direto, cultivo mínimo e preparo convencional) com quatro repetições.

O solo em que foram instalados os experimentos foi classificado como Argissolo Vermelho-Amarelo plíntico (Santos et al., 2013) e os atributos químicos do solo, na camada $0-20 \mathrm{~cm}$ de profundidade, apresentavam os seguintes conteúdos: $\mathrm{pH}\left(\mathrm{em} \mathrm{H}_{2} \mathrm{O}\right)$ de 4,6; 5,0 mg dm $\mathrm{mg}^{-3}$ de (resina); 0,20 $\mathrm{cmol}_{\mathrm{c}} \mathrm{dm}^{-3}$ de $\mathrm{K} ; 1,0 \mathrm{cmol}_{\mathrm{c}} \mathrm{dm}^{-3}$ de $\mathrm{Ca} ; 1,3 \mathrm{cmol}_{\mathrm{c}} \mathrm{dm}^{-3}$ de $\mathrm{Mg}$; $0,70 \mathrm{cmol}_{\mathrm{c}} \mathrm{dm}^{-3} \mathrm{de} \mathrm{Al} ; 1,86 \mathrm{cmol}_{\mathrm{c}} \mathrm{dm}^{-3} \mathrm{de} \mathrm{H}+\mathrm{Al}$; soma de bases de 2,54 $\mathrm{cmol}_{\mathrm{c}} \mathrm{dm}^{-3}$; T de 4,4 $\mathrm{cmol}_{\mathrm{c}} \mathrm{dm}^{-3} ; \mathrm{V}$ de $58 \%$; e matéria orgânica de $12,1 \mathrm{~g} \mathrm{~kg}^{-1}$.

As duas cultivares de alface avaliadas, ambas de coloração verde clara e ciclo médio de 60 a 70 dias, foram cultivadas em sistema orgânico. Os níveis de sombreamento dos tratamentos foram determinados com fotômetro medidor de iluminância, em um dia sem nebulosidade, ao meio dia, com os resultados expressos em lux e transformados para percentagem, tendo como referência o ambiente a pleno sol.

O tratamento com $35 \%$ de sombreamento foi realizado em casa de vegetação de 22,0x6,9 m, com 2,0 $\mathrm{m}$ de pé direito e $3,5 \mathrm{~m}$ de altura central, com lanternim, coberta com filme de polietileno transparente de $100 \mu \mathrm{m}$ de espessura e com as laterais abertas. Os demais tratamentos foram realizados em campo.

No tratamento com $50 \%$ de sombreamento, colocouse uma tela agrícola preta com $50 \%$ de atenuação da radiação, medindo $7,2 \mathrm{~m}$ de largura por $30 \mathrm{~m}$ de comprimento, a 2,0 $\mathrm{m}$ de altura.

No tratamento com $52 \%$ de sombreamento, a latada de maracujazeiro (Passiflora edulis Sims f. flavicarpa) foi instalada a $2,0 \mathrm{~m}$ de altura do solo no espaçamento de $2,0 \times 5,0 \mathrm{~m}$, e as plantas foram conduzidas na horizontal, com poda para permitir a produção de frutos e a passagem de luz para as plantas de alface. $\mathrm{O}$ tratamento a pleno sol foi realizado em área não protegida e considerado como controle.

O plantio foi efetuado em quatro linhas dispostas no espaçamento de $0,30 \times 0,30 \mathrm{~m}$, em parcelas com $1,8 \mathrm{~m}$ de comprimento por 1,2 $\mathrm{m}$ de largura. A área ocupada pelas seis plantas centrais de cada linha foi considerada como área útil de avaliação, o que totalizou 24 plantas por subparcela.

Nos experimentos realizados no período chuvoso, o transplantio das mudas foi feito em 9/2/2009 e a colheita em 13/3/2009. Nos experimentos no período 
de estiagem, o transplantio foi realizado em 29/5/2009 e a colheita em 6/7/2009.

A semeadura foi feita em bandejas de 128 células, com substrato à base de solo da superfície, composto orgânico, casca de arroz carbonizada, carvão vegetal na proporção de 3:3:3:1 v/v, $1,5 \mathrm{~kg} \mathrm{~m}^{-3}$ de termofosfato Yoorin (17,5\% de $\mathrm{P}_{2} \mathrm{O}_{5}$ total e $13 \%$ de $\mathrm{P}_{2} \mathrm{O}_{5}$ solúvel em ácido cítrico) e $1,0 \mathrm{~kg} \mathrm{~m}^{-3}$ de calcário $(29 \%$ de $\mathrm{CaO}$, $21 \%$ de $\mathrm{MgO}$ e PRNT de 90,5\%).

O composto orgânico foi proveniente de processo de compostagem de grama batatais (Paspalum notatum Flugge) e esterco bovino, em camadas alternadas de 5:1 v/v, por 120 dias, contendo: N, 1,13\%; P (ácido cítrico), $1,33 \%$; $\mathrm{K}\left(\mathrm{H}_{2} \mathrm{O}\right), 0,18 \%$; Ca, 3,36\%; $\mathrm{Mg}, 0,20 \%$; , $0,10 \%$; $\mathrm{pH}, 6,55$; matéria orgânica, $11,97 \%$; cinzas, $88,61 \%$; densidade, $350 \mathrm{~kg} \mathrm{~m}^{-3}$; relação $\mathrm{C} / \mathrm{N}, 6,11$.

O solo utilizado no substrato foi coletado no horizonte $\mathrm{A}$, da mesma área de cultivo do experimento. Este substrato apresentou $\mathrm{pH}\left(\mathrm{em} \mathrm{H}_{2} \mathrm{O}\right) 7,5 ; \mathrm{P}$ (ácido cítrico) $5,9 \mathrm{mg} \mathrm{L}^{-1} ; \mathrm{K}, 184,0 \mathrm{mg} \mathrm{L}^{-1} ; \mathrm{Ca}, 108,0 \mathrm{mg} \mathrm{L}^{-1} ; \mathrm{Mg}, 408,0$ $\mathrm{mg} \mathrm{L}^{-1} ; \mathrm{S}, 36,3 \mathrm{mg} \mathrm{L}^{-1} ; \mathrm{B}, 0,21 \mathrm{mg} \mathrm{L}^{-1}$; $\mathrm{Cu}, 0,02 \mathrm{mg} \mathrm{L}^{-1}$; $\mathrm{Fe}, 3,76 \mathrm{mg} \mathrm{L}^{-1}$; Mn, 0,12 $\mathrm{mg} \mathrm{L}^{-1}$ e Na, 10,0 $\mathrm{mg} \mathrm{L}^{-1}$.

O preparo convencional do solo consistiu de capina e construção de canteiros com enxada manual, a $20 \mathrm{~cm}$ de altura. No cultivo mínimo, o solo foi revolvido e incorporou-se o adubo até $10 \mathrm{~cm}$ de profundidade. No plantio direto, o solo não foi revolvido, a vegetação espontânea foi cortada com auxílio de enxada manual e dessecada naturalmente, e o adubo foi distribuído na superfície. A adubação foi feita com $17 \mathrm{Mg} \mathrm{ha}^{-1}$ de composto orgânico com $50 \%$ de umidade, incorporado no preparo convencional. Após o transplantio das mudas de alface, o solo foi coberto com palha de bambu (Bambusa tuldoides Munro) seco.

As irrigações foram realizadas por sistema de microaspersão, tendo-se aplicado lâmina média de
6,0 $\mathrm{mm}$ por dia, de acordo com Lédo et al. (2000). Durante o período chuvoso, em casa de vegetação, aplicou-se lâmina total de $192 \mathrm{~mm}$ em 31 dias de cultivo; nos demais ambientes (tela, latada e a pleno sol), $72 \mathrm{~mm}$; e, nos 12 dias em que não ocorreu precipitação, 195,8 mm. No período de estiagem, em casa de vegetação, aplicou-se $228 \mathrm{~mm}$ em 38 dias de cultivo; e nos demais ambientes, $216 \mathrm{~mm}$ nos 36 dias em que não ocorreu precipitação e $54,5 \mathrm{~mm}$ no restante do período.

A limpeza nos canteiros foi efetuada para eliminar plantas espontâneas nas entrelinhas e diminuir a competição com a cultura principal, inclusive no plantio direto que apresentou infestação de plantas espontâneas.

Para prevenir problemas fitossanitários, foi feita a aplicação de calda sulfocálcica a $2 \%$, uma vez aos 15 dias após o plantio, em cada época e em todos os ambientes de cultivo.

A colheita foi realizada de forma manual durante o período de máximo desenvolvimento vegetativo da alface, antes do início do pendoamento.

Para determinar a massa da matéria fresca total da planta, foram pesadas as seis plantas úteis de cada parcela, sem as folhas sujas, senescentes e doentes. Já para obter a massa da matéria seca da parte aérea, as plantas foram acondicionadas em sacos de papel e secas em estufa com circulação forçada de ar, a $70^{\circ} \mathrm{C}$, até massa constante.

$\mathrm{Na}$ análise estatística, os dados foram submetidos à verificação da normalidade dos resíduos (Shapiro \& Wilk, 1965) e à homogeneidade das variâncias (Bartlett, 1937). Em seguida, foi realizada análise de variância para cada experimento, e, após observada a variação mínima entre o maior e o menor quadrado médio do resíduo dos quatro tratamentos (Zimmermann, 2014), foi feita análise de variância conjunta para verificar os efeitos isolados ou combinados dos fatores avaliados:

Tabela 1. Dados meteorológicos mensal das épocas de plantio, obtidos da estação meteorológica da Universidade Federal do Acre, localizada a $50 \mathrm{~m}$ do experimento.

\begin{tabular}{|c|c|c|c|c|c|c|c|}
\hline \multirow[t]{2}{*}{ Épocas } & \multirow{2}{*}{$\begin{array}{l}\text { Chuvas } \\
(\mathrm{mm})\end{array}$} & \multicolumn{3}{|c|}{ Temperatura $\left({ }^{\circ} \mathrm{C}\right)$} & \multirow{2}{*}{$\begin{array}{c}\text { UR do } \operatorname{ar}^{(1)} \\
(\%)\end{array}$} & \multirow{2}{*}{$\begin{array}{c}\text { Evapotranspiração }^{(1)} \\
(\mathrm{mm})\end{array}$} & \multirow{2}{*}{$\begin{array}{l}\text { Insolação } \\
\text { (h) }\end{array}$} \\
\hline & & Máxima & Mínima & Média & & & \\
\hline \multicolumn{8}{|l|}{ Chuvosa } \\
\hline Fev./2009 & 286,0 & 30,9 & 22,3 & 25,6 & 94,0 & 1,4 & 101,1 \\
\hline Mar./2009 & 247,0 & 30,2 & 24,2 & 26,2 & 90,6 & 1,6 & 98,5 \\
\hline \multicolumn{8}{|l|}{ Estiagem } \\
\hline Maio/2009 & 153,0 & 31,3 & 24,4 & 26,5 & 86,0 & 1,5 & 184,4 \\
\hline Jun./2009 & 27,0 & 32,5 & 25,6 & 27,5 & 60,5 & 1,3 & 202,3 \\
\hline Jul./2009 & 31,0 & 32,7 & 25,8 & 27.6 & 65,3 & 1,2 & 213,7 \\
\hline
\end{tabular}

${ }^{(1)}$ Média diária do mês. 
níveis de sombreamento, sistemas de preparo do solo e épocas de plantio.

\section{Resultados e Discussão}

No tratamento com $35 \%$ de sombreamento, em casa de vegetação, as duas cultivares avaliadas apresentaram massa fresca da parte aérea (Tabela 2) e produtividade (Tabela 3) superiores às das cultivadas sob todos os outros níveis de sombreamento (tela e espaldeira) e sistemas de preparo do solo. Sobressaiuse o binômio: sistema de preparo plantio direto e duas épocas de plantio, exceto para a cultivar Vera, em que os resultados mais promissores em relação à massa fresca e à produtividade na época de estiagem foram observados no sistema de preparo cultivo mínimo, ao invés de no plantio direto.

Lédo et al. (2000) constataram que o cultivo de alface não protegido interfere negativamente na produtividade, em razão das condições de alta precipitação típicas do Acre, bem como da temperatura e da radiação solar (Puiatti \& Finger, 2005), principalmente pela ocorrência de fotoinibição, o que causa baixo rendimento da alface em períodos de altas temperaturas e luminosidade (Fu et al., 2012).

Além de reduzir o efeito de fotoinibição, o sombreamento, por cobertura de polietileno ou tela

Tabela 2. Massa de matéria fresca (g por planta) comercial da parte aérea de plantas de alface (Lactuca sativa) cultivadas sob diferentes níveis de sombreamento, sistemas de preparo do solo e épocas de plantio ${ }^{(1)}$.

\begin{tabular}{|c|c|c|c|c|c|c|c|c|}
\hline \multirow{2}{*}{$\begin{array}{l}\text { Sistemas de } \\
\text { preparo } \\
\text { do solo }\end{array}$} & \multicolumn{4}{|c|}{ Período chuvoso } & \multicolumn{4}{|c|}{ Período de estiagem } \\
\hline & $\begin{array}{c}\text { Casa de } \\
\text { vegetação }\end{array}$ & Tela & Espaldeira & Pleno sol & $\begin{array}{c}\text { Casa de } \\
\text { vegetação }\end{array}$ & Tela & Espaldeira & Pleno sol \\
\hline & \multicolumn{8}{|c|}{ 'Vera' (Alface crespa) } \\
\hline Plantio direto & $119,0 \mathrm{aA} a$ & $94,0 \mathrm{aB} a$ & $25,0 \mathrm{aC} b$ & $39,4 \mathrm{aC} b$ & $126,7 \mathrm{aA} a$ & $69,2 \mathrm{bB} b$ & $76,3 \mathrm{aB} a$ & $111,4 \mathrm{aA} a$ \\
\hline Cultivo mínimo & $87,0 \mathrm{bA} b$ & $84,1 \mathrm{aA} b$ & $21,7 \mathrm{aB} b$ & $4,2 \mathrm{bCa}$ & $135,4 \mathrm{aA} a$ & $112,5 \mathrm{aA} a$ & $54,8 \mathrm{bB} a$ & $42,7 \mathrm{cB} a$ \\
\hline Convencional & $91,5 \mathrm{bA} b$ & $50,6 \mathrm{bB} b$ & $33,8 \mathrm{aC} b$ & $6,6 \mathrm{bC} b$ & $118,3 \mathrm{aA} a$ & $96,7 \mathrm{aA} a$ & $85,2 \mathrm{aB} a$ & $76,1 \mathrm{bB} a$ \\
\hline \multirow[t]{2}{*}{$\mathrm{CV}(\%)$} & \multicolumn{8}{|c|}{5,25} \\
\hline & \multicolumn{8}{|c|}{ 'Baba de Verão' (Alface lisa) } \\
\hline Plantio direto & $185,7 \mathrm{aA} a$ & $87,5 \mathrm{aB} a$ & $35,2 \mathrm{aB} a$ & $61,7 \mathrm{aB} a$ & $176,7 \mathrm{aA} a$ & $87,8 \mathrm{aB} a$ & $87,3 \mathrm{aB} a$ & $53,1 \mathrm{aB} a$ \\
\hline Cultivo mínimo & $183,0 \mathrm{aA} a$ & $76,1 \mathrm{aB} a$ & $44,7 \mathrm{aB} a$ & $28,1 \mathrm{aB} a$ & $142,3 \mathrm{aA} a$ & $124,8 \mathrm{aA} a$ & $100,7 \mathrm{aA} a$ & $43,1 \mathrm{aA} a$ \\
\hline Convencional & $115,4 \mathrm{aA} a$ & $78,6 \mathrm{aA} a$ & $101,7 \mathrm{aA} a$ & $32,8 \mathrm{aB} a$ & $172,3 \mathrm{aA} a$ & $141,1 \mathrm{aA} a$ & $106,7 \mathrm{aA} a$ & $98,3 \mathrm{aA} a$ \\
\hline $\mathrm{CV}(\%)$ & \multicolumn{8}{|c|}{6,38} \\
\hline
\end{tabular}

Tabela 3. Produtividade $\left(\mathrm{kg} \mathrm{ha}^{-1}\right)$ de plantas de alface (Lactuca sativa) cultivadas sob diferentes níveis de sombreamento, sistemas de preparo do solo e épocas de plantio ${ }^{(1)}$.

\begin{tabular}{|c|c|c|c|c|c|c|c|c|}
\hline \multirow{2}{*}{$\begin{array}{l}\text { Sistemas de } \\
\text { preparo } \\
\text { do solo }\end{array}$} & \multicolumn{4}{|c|}{ Período chuvoso } & \multicolumn{4}{|c|}{ Período de estiagem } \\
\hline & $\begin{array}{c}\text { Casa de } \\
\text { vegetação }\end{array}$ & Tela & Espaldeira & Pleno sol & $\begin{array}{c}\text { Casa de } \\
\text { vegetação }\end{array}$ & Tela & Espaldeira & Pleno sol \\
\hline & \multicolumn{8}{|c|}{ 'Vera' (Alface crespa) } \\
\hline Plantio direto & $9.223 \mathrm{aA} a$ & $7.283 \mathrm{aB} a$ & $1.938 \mathrm{aC} b$ & $3.057 \mathrm{aD} b$ & $9.819 \mathrm{aA} a$ & $5.362 \mathrm{bB} b$ & $5.911 \mathrm{aB} a$ & $8.635 \mathrm{aA} a$ \\
\hline Mínimo & $6.742 \mathrm{bA} b$ & $6.519 \mathrm{aA} b$ & $1.678 \mathrm{aB} b$ & $323 \mathrm{bC} b$ & $10.497 \mathrm{aA} a$ & $8.721 \mathrm{aA} a$ & $4.248 \mathrm{bB} a$ & $3.306 \mathrm{cB} a$ \\
\hline Convencional & $7.089 \mathrm{bA} b$ & $3.320 \mathrm{bB} b$ & $2.616 \mathrm{aC} b$ & $512 \mathrm{bD} b$ & $9.173 \mathrm{aA} a$ & $7.494 \mathrm{aA} a$ & $6.606 \mathrm{aB} a$ & $5.900 \mathrm{bB} a$ \\
\hline \multirow[t]{2}{*}{ CV (\%) } & \multicolumn{8}{|c|}{7,39} \\
\hline & \multicolumn{8}{|c|}{ 'Baba de Verão' (Alface lisa) } \\
\hline Direto & $14.394 \mathrm{aA} a$ & $6.783 \mathrm{aB} a$ & $2.729 \mathrm{aB} a$ & $4.779 \mathrm{aB} a$ & $13.695 \mathrm{aA} a$ & $6.804 \mathrm{aB} a$ & $6.767 \mathrm{aB} a$ & $4.113 \mathrm{aB} a$ \\
\hline Mínimo & $14.189 \mathrm{aA} a$ & $5.901 \mathrm{aB} a$ & $3.468 \mathrm{aB} a$ & $2.176 \mathrm{aB} a$ & $11.030 \mathrm{aA} a$ & $9.674 \mathrm{aA} a$ & $7.801 \mathrm{aA} a$ & $3.340 \mathrm{aA} a$ \\
\hline Convencional & $8.942 \mathrm{aA} a$ & $6.093 \mathrm{aA} a$ & $7.882 \mathrm{aA} a$ & $2.543 \mathrm{aA} a$ & $13.356 \mathrm{aA} a$ & $10.934 \mathrm{aA} a$ & $8.269 \mathrm{aA} a$ & $7.623 \mathrm{aA} a$ \\
\hline CV (\%) & \multicolumn{8}{|c|}{9,88} \\
\hline
\end{tabular}

${ }^{(1)}$ Médias seguidas de letras distintas, minúsculas nas colunas, diferem entre os sistemas de preparo do solo; maiúsculas nas linhas, entre os níveis de sombreamento; e itálicas minúsculas, entre as épocas de plantio para a mesma cultivar e os mesmos sistema de preparo do solo e nível de sombreamento, pelo teste de Scott \& Knott, a 5\% de probabilidade. 
(Bezerra Neto et al., 2005; Ferreira et al., 2009), promove produção de folhas maiores, o que contribui para maior quantidade de massa fresca por planta (Radin et al., 2004), ao diminuir o tecido paliçádico e aumentar o lacunoso, o que aumenta a área foliar específica (Puiatti \& Finger, 2005). Em plantas de taro [Colocasia esculenta (L.) Schott], o sombreamento promove mudanças na proporção de células e tecidos, como redução da espessura da folha, do parênquima paliçádico, do aerênquima e da densidade de estômatos, o que interfere na sua capacidade fotossintética e na redistribuição de fotoassimilados (Gondim et al., 2008).

Em relação ao sistema de preparo do solo cultivo mínimo, tanto a massa fresca (Tabela 2) quanto a produtividade (Tabela 3) da cultivar Vera foram semelhantes em casa de vegetação e sob tela, para as duas épocas de plantio. A cultivar Baba de Verão apresentou desempenho similar em casa de vegetação e sob tela, com preparo mínimo e convencional do solo, para as duas épocas de plantio, exceto para cultivo mínimo no período chuvoso (Tabelas 2 e 3 ).

Apesar da maior massa fresca das plantas de alface em casa de vegetação, o cultivo sob tela de sombreamento proporcionou mais economia de água e energia para irrigação. No período chuvoso, ocorreu precipitação de $195 \mathrm{~mm}$ e aplicou-se lâmina total de irrigação de $192 \mathrm{~mm}$, em casa de vegetação, e de $72 \mathrm{~mm}$ nos demais ambientes. No período de estiagem, ocorreu precipitação de $54,5 \mathrm{~mm}$ e aplicou-se lâmina total de irrigação de $228 \mathrm{~mm}$, em casa de vegetação, e de $216 \mathrm{~mm}$ nos demais ambientes.

A época de plantio influenciou a massa fresca das plantas da cultivar Vera, que foi maior no período de estiagem, exceto no cultivo em casa de vegetação, em plantio direto. Apenas o cultivo sob tela, em plantio direto, proporcionou menor massa fresca durante $o$ período de estiagem (Tabela 2).

A época de plantio influenciou a produtividade da cultivar Vera, que apresentou maior produtividade no período de estiagem, exceto quando cultivada em casa de vegetação, em sistema plantio direto (Tabela 3). Já para a cultivar Baba de Verão, não foi observada diferença na produtividade entre as épocas de cultivo.

A menor precipitação na estiagem favoreceu a produtividade da alface, uma vez que o excesso de água altera o equilíbrio nos seguintes aspectos: químico, com maior teor de nitrogênio e difusão de nutrientes; físico, com menor aeração do solo; e biológico, com menor taxa de respiração. Isso torna as plantas mais suscetíveis a doenças, assim como aos danos físicos causados pelos pingos e respingos das chuvas (Filgueira, 2008). Além disso, nessa época, Ferreira et al. (2014) relataram que condições de menor temperatura do ar e maior luminosidade contribuíram para o melhor desempenho da alface, principalmente por esta ser uma planta de origem mediterrânea que se adapta melhor a temperaturas amenas (Sala \& Costa, 2012).

O plantio direto proporcionou maior massa fresca (Tabela 2) e produtividade (Tabela 3) de alface 'Vera' em cultivo em casa de vegetação, em ambas as épocas de plantio. Essa vantagem do plantio direto pode ser atribuída à manutenção da palhada, ao efeito residual das adubações, à melhoria da estrutura do solo, à maior disponibilidade de água, ao aumento da atividade microbiana (Brancalião \& Moraes, 2008; Wang et al., 2008; Mota et al., 2010; Veiga et al., 2010) e ao menor custo de produção (Araújo Neto et al., 2012).

Em cultivo em espaldeira, a massa fresca (Tabela 2) e a produtividade (Tabela 3 ) das plantas de alface foram semelhantes em plantio direto e preparo mínimo, no período chuvoso, para as duas cultivares estudadas. Resultado similar foi observado, no período de estiagem, entre plantio direto e preparo convencional. Ferreira et al. (2014) também não verificaram, na estiagem, diferença entre plantio direto e preparo convencional do solo em relação ao desempenho produtivo das plantas.

A massa de matéria seca da parte aérea das cultivares de alface Baba de Verão e Vera foi maior no cultivo em casa de vegetação, seguida do cultivo sob tela de sombreamento que, por sua vez, também foi superior aos cultivos em espaldeira de maracujazeiro e a pleno sol, os quais não diferiram entre si (Tabela 4). A menor

Tabela 4. Massa de matéria seca da parte aérea de cultivares de alface (Lactuca sativa) cultivadas sob diferentes níveis de sombreamento $^{(1)}$.

\begin{tabular}{lcc}
\hline $\begin{array}{l}\text { Níveis de } \\
\text { sombreamento }\end{array}$ & $\begin{array}{c}\text { 'Baba de Verão' } \\
\text { (lisa) }\end{array}$ & $\begin{array}{c}\text { 'Vera' } \\
\text { (crespa) }\end{array}$ \\
\hline Casa de vegetação (35\%) & $5,91 \mathrm{a}$ & $5,04 \mathrm{a}$ \\
Tela de sombreamento (50\%) & $4,15 \mathrm{~b}$ & $2,98 \mathrm{~b}$ \\
Espaldeira de maracujazeiro (52\%) & $2,83 \mathrm{c}$ & $2,03 \mathrm{c}$ \\
Pleno sol & $2,51 \mathrm{c}$ & $2,04 \mathrm{c}$ \\
\hline CV (\%) & 7,39 & 7,38 \\
\hline
\end{tabular}

${ }^{(1)}$ Médias seguidas de letras distintas, minúsculas nas colunas, diferem pelo teste de Tukey, a $5 \%$ de probabilidade. 
radiação sobre a cultura da alface, obtida em casa de vegetação e sob tela, promove produção de folhas maiores e mais tenras, em razão da diminuição do tecido paliçádico e do aumento do lacunoso, o que proporciona maior área foliar específica, ou seja, relação superfície da folha/massa seca da folha (Puiatti \& Finger, 2005). A fotossíntese em ambientes com menos luz é compensada pela maior radiação difusa, o que contribui para maior quantidade de massa por planta (Radin et al., 2004).

No período de estiagem, houve maior acúmulo de massa de matéria seca em plantas da cultivar Baba de Verão cultivadas em preparo convencional do solo (Tabela 5). No entanto, no período chuvoso, não houve diferença entre os sistemas de preparo do solo. Ferreira et al. (2014) observaram maior acúmulo de massa seca de alface, em preparo convencional do solo, em casa de vegetação, na primeira época de cultivo (estiagem); contudo, nas duas seguintes (chuvosa e estiagem), não constataram diferença entre o preparo convencional do solo e o plantio direto. A maior mineralização e solubilização de compostos orgânicos em solo com preparo convencional é consequência do adubo no solo revolvido, da quebra de agregados e do aumento da aeração (Leite et al., 2009), o que possibilita maior absorção de nutrientes pelas plantas, com acúmulo de massa de matéria seca.

Tabela 5. Massa de matéria seca da parte aérea da cultivar de alface (Lactuca sativa) Baba de Verão, cultivada em diferentes sistemas de preparo do solo e épocas de plantio ${ }^{(1)}$.

\begin{tabular}{|c|c|c|c|}
\hline $\begin{array}{l}\text { Época de } \\
\text { plantio }\end{array}$ & Convencional & $\begin{array}{l}\text { Plantio direto } \\
\text {-(g por planta) }\end{array}$ & Cultivo mínimo \\
\hline Chuvosa & $2,73 \mathrm{bA}$ & $3,15 \mathrm{bA}$ & $2,66 \mathrm{bA}$ \\
\hline Estiagem & $5,47 \mathrm{aA}$ & $4,35 \mathrm{aB}$ & $5,46 \mathrm{aA}$ \\
\hline
\end{tabular}

${ }^{(1)}$ Médias seguidas de letras distintas, minúsculas nas colunas e maiúsculas nas linhas, diferem pelos testes F e de Scott \& Knott, respectivamente, a $5 \%$ de probabilidade.

Tabela 6. Massa de matéria seca da parte aérea de cultivares de alface (Lactuca sativa) cultivadas sob diferentes níveis de sombreamento ${ }^{(1)}$.

\begin{tabular}{lcc}
\hline $\begin{array}{l}\text { Época de } \\
\text { plantio }\end{array}$ & 'Baba de Verão' (lisa) & 'Vera' (crespa) \\
\hline Chuvoso & $---c-1,85 \mathrm{~b}$ & $2,39 \mathrm{~b}$ \\
Estiagem & $4,86 \mathrm{a}$ & $3,66 \mathrm{a}$ \\
\hline
\end{tabular}

${ }^{(1)}$ Médias seguidas de letras distintas, minúsculas nas colunas, diferem pelo teste $\mathrm{F}$, a $5 \%$ de probabilidade.
No período de estiagem, as cultivares Baba de Verão e Vera acumularam maior quantidade de massa de matéria seca na parte aérea do que no período chuvoso (Tabela 6). Resultado semelhante foi obtido por Ferreira et al. (2014), que atribuíram esse fenômeno a maior capacidade de as plantas produzirem fotossintatos. Segundo Fu \& Wu (2012), como a alface apresenta fotoinibição, condições de temperatura e luminosidade amenas são importantes para maior eficiência do fotossistema, carboxilação do $\mathrm{CO}_{2}$ e acúmulo de matéria seca.

O maracujazeiro orgânico, cultivado em espaldeira, apresentou produtividade de $14.161 \mathrm{~kg} \mathrm{ha}^{-1}$, equivalente à média nacional de $14.046 \mathrm{~kg} \mathrm{ha}^{-1}$, mas superior à média estadual de $7.600 \mathrm{~kg} \mathrm{ha}^{-1} \mathrm{e}$ à obtida nas mesmas condições em espaldeira vertical com um fio de arame, de $4.361 \mathrm{~kg} \mathrm{ha}^{-1}$ (Maracujá, 2012). Portanto, apesar do baixo desempenho da produção de alface em espaldeira de maracujazeiro-amarelo, a alta produtividade de frutos contribui para o aumento da receita, o que regula o negócio da produção dessa olerícola (Araújo Neto et al., 2012). Esse fato é importante para sistemas orgânicos de produção, principalmente em agriculturas de baixo uso de insumos e de base familiar, que podem, conforme Grisa (2007), promover certa flexibilidade nas relações com o mercado.

\section{Conclusões}

1. O cultivo em casa de vegetação proporciona maior massa de matéria fresca e produtividade de alface (Lactuca sativa) 'Vera', e desempenho similar ao observado sob tela de sombreamento, com preparo mínimo do solo, para as duas épocas de plantio avaliadas.

2. Ocultivo a pleno sol, em plantio direto, proporciona maior massa de matéria fresca e produtividade de alface 'Vera', para o período de estiagem.

3. A massa de matéria seca da parte aérea das cultivares de alface Baba de Verão e Vera é maior em cultivo em casa de vegetação, seguida do cultivo sob tela de sombreamento.

\section{Agradecimentos}

À Coordenação de Aperfeiçoamento de Pessoal de Nível Superior (Capes) e ao Conselho Nacional de Desenvolvimento Científico e Tecnológico (CNPq), pela concessão de bolsas.

\footnotetext{
Pesq. agropec. bras., Brasília, v.50, n.6, p.468-474, jun. 2015
} DOI: 10.1590/S0100-204X2015000600005 


\section{Referências}

ARAÚJO NETO, S.E. de; SILVA, E.M.N.C. de P. da; FERREIRA, R.L.F.; CECÍLIO FILHO, A.B. Rentabilidade da produção orgânica de alface em função do ambiente, preparo do solo e época de plantio. Revista Ciência Agronômica, v.43, p.783-791, 2012. DOI: $10.1590 / \mathrm{S} 1806-66902012000400021$.

BARBOSA, S. de C.; MATTEUCCI, M.B. de A.; LEANDRO, W.M.; LEITE, A.F.; CAVALCANTE, E.L.S.; ALMEIDA, G.Q.E. de. Perfil do consumidor e oscilações de preços de produtos agroecológicos. Pesquisa Agropecuária Tropical, v.41, p.602-609, 2011. DOI: 10.5216/pat.v41i4.11854.

BARTLETT, M.S. Properties of sufficiency and statistical tests. Proceedings of the Royal Society of London, v.160, p.268-282, 1937. DOI: 10.1098/rspa.1937.0109.

BEZERRA NETO, F.; ROCHA, R.C.C.; NEGREIROS, M.Z. de; ROCHA, R.H.C.; QUEIROGA, R.C.F. de. Produtividade de alface em função de condições de sombreamento, temperatura e luminosidade elevadas. Horticultura Brasileira, v.23, p.189-192, 2005. DOI: 10.1590/S0102-05362005000200005.

BRANCALIÃO, S.R.; MORAES, M.H. Alterações de alguns atributos físicos e das frações húmicas de um Nitossolo Vermelho na sucessão milheto-soja em sistema plantio direto. Revista Brasileira de Ciência do Solo, v.32, p.393-404, 2008. DOI: 10.1590/S0100-06832008000100037.

FERREIRA, R.L.F.; ALVES, A.S.S.C.; ARAÚJO NETO, S.E.; KUSDRA, J.F.; REZENDE, M.I.F.L. Produção orgânica de alface em diferentes épocas de cultivo e sistemas de preparo e cobertura de solo. Bioscience Journal, v.30, p.1017-1023, 2014.

FERREIRA, R.L.F.; ARAÚJO NETO, S.E.; SILVA, S.S. da; ABUD, E.A.; REZENDE, M.I. de F.L.; KUSDRA, J.F. Combinações entre cultivares, ambientes, preparo e cobertura do solo em características agronômicas de alface. Horticultura Brasileira, v.27, p.383-388, 2009. DOI: 10.1590/S0102-05362009000300023.

FILGUEIRA, F.A.R. Novo manual de olericultura: agrotecnologia moderna na produção e comercialização de hortaliças. 3.ed. Viçosa: Ed. da UFV, 2008. 421p.

FU, W.; LI, P.; WU, Y. Effects of different light intensities on chlorophyll fluorescence characteristics and yield in lettuce. Scientia Horticulturae, v.135, p.45-51, 2012. DOI: $10.1016 / \mathrm{j}$. scienta.2011.12.004.

GONDIM, A.R. de O.; PUIATTI, M.; VENTRELLA, M.C.; CECON, P.R. Plasticidade anatômica da folha de taro cultivado sob diferentes condições de sombreamento. Bragantia, v.67, p.1037-1045, 2008. DOI: 10.1590/S0006-87052008000400028.

GRISA, C. Para além da alimentação: papéis e significados da produção para autoconsumo na agricultura familiar. Revista Extensão Rural, v.14, p.5-35, 2007.

LÉDO, F.J. da S.; SOUSA, J.A. de; SILVA, M.R. da. Desempenho de cultivares de alface no Estado do Acre. Horticultura Brasileira, v.18, p.225-228, 2000. DOI: 10.1590/S0102-05362000000300017.
LEITE, L.F.C.; CARDOSO, M.J.; COSTA, D.B.; FREITAS, R. de C.A. de; RIBEIRO, V.Q.; GALVÃO, S.R. da S. Estoques de C e $\mathrm{N}$ e produtividade do milho sob sistemas de preparo e adubação nitrogenada em um Latossolo Vermelho-Amarelo do cerrado piauiense. Ciência Rural, v.39, p.2460-2466, 2009. DOI: 10.1590/ S0103-84782009000900012.

MARACUJÁ. In: AGRIANUAL 2012: anuário da agricultura brasileira. São Paulo: Informa Economics FNP, 2012. p.350.

MOTA, J.C.A.; LIBARDI, P.L.; BRITO, A. dos S.; ASSIS JÚNIOR, R.N. de; AMARO FILHO, J. Armazenagem de água e produtividade de meloeiro irrigado por gotejamento, com a superfície do solo coberta e desnuda. Revista Brasileira de Ciência do Solo, v.34, p.1721-1731, 2010. DOI: 10.1590/ S0100-06832010000500024.

PUIATTI, M.; FINGER, F.L. Fatores climáticos. In: FONTES, P.C.R. Olericultura: teoria e prática. Viçosa: Ed. da UFV, 2005. p.17-30.

RADIN, B.; REISSER JÚNIOR, C.; MATZENAUER, R.; BERGAMASHI, H. Crescimento de cultivares de alface conduzidas em estufa e a campo. Horticultura Brasileira, v.22, p.178-181, 2004. DOI: 10.1590/S0102-05362004000200003.

SALA, F.C.; COSTA, C.P. da. Retrospectiva e tendência da alfacicultura brasileira. Horticultura Brasileira, v.30, p.187-194, 2012. DOI: 10.1590/S0102-05362012000200002.

SANTOS, H.G. dos; JACOMINE, P.K.T.; ANJOS, L.H.C. dos; OLIVEIRA, V.A. de; LUMBRERAS, J.F.; COELHO, M.R.; ALMEIDA, J.A. de; CUNHA, T.J.F.; OLIVEIRA, J.B. de (Ed.). Sistema brasileiro de classificação de solos. 3.ed. Brasília: Embrapa, 2013. 353p.

SHAPIRO, S.S.; WILK, M.B. An analysis of variance test for normality (complete samples). Biometrika, v.52, p.591-611, 1965. DOI: 10.1093/biomet/52.3-4.591.

SILVA, E.M.N.C.P. da; FERREIRA, R.L.F.; ARAÚJO NETO, S.E. de; TAVELLA, L.B.; SOLINO, A.J.S. Qualidade de alface crespa cultivada em sistema orgânico, convencional e hidropônico. Horticultura Brasileira, v.29, p.242-245, 2011. DOI: 10.1590/ S0102-05362011000200019.

SOUZA, J.L. de. Agricultura orgânica: tecnologias para produção de alimentos saudáveis. Vitória: Incaper, 2005. v.2, 256p.

VEIGA, M. da; REINERT, D.J.; REICHERT, J.M. Tillage systems and nutrient sources affecting soil cover, temperature and moisture in a clayey Oxisol under corn. Revista Brasileira de Ciência do Solo, v.34, p.2011-2020, 2010. DOI: 10.1590/ S0100-06832010000600025.

WANG, Q.; BAI, Y.; GAO, H.; HE, J.; CHEN, H.; CHESNEY, R.C.; KUHN, N.J. Soil chemical properties and microbial biomass after 16 years of no-tillage farming on the Loess Plateau, China. Geoderma, v.144, p.502-508, 2008. DOI: 10.1016/j. geoderma.2008.01.003.

ZIMMERMANN, F.J.P. Estatística aplicada à pesquisa agrícola. 2.ed. Brasília: Embrapa, 2014. 582p. 